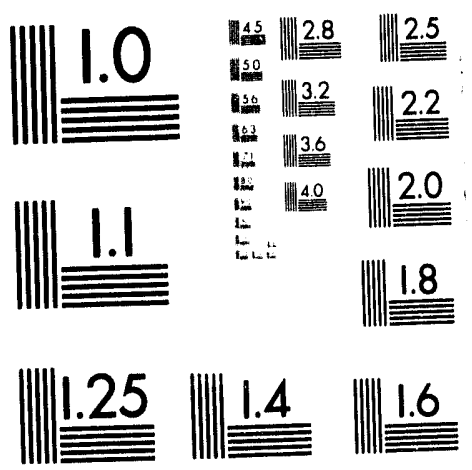



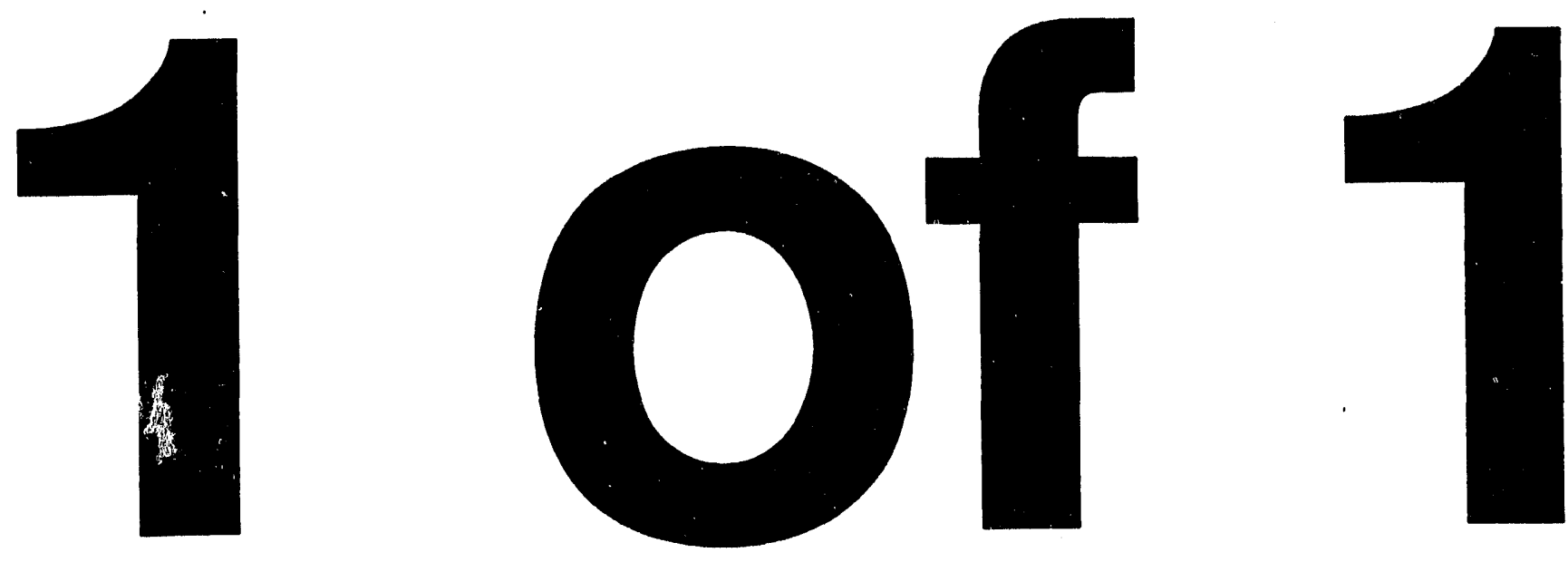


\section{PROBLEMS AND SOLUTIONS IN APPLICATION OF IEEE STANDARDS AT SAVANNAH RIVER SITE, DEPARTMENT OF ENERGY (DOE) OWNED NUCLEAR FACILITIES (U)}

by

\section{Y.S. Le日}

Westinghouse Savannah River Company

Savannah River Site

Aiken, South Carolina 29808

A document prepared for:

presentation and publication at the 1993 IEEE Nuclear Science Symposium and Medical Imaging Conference at San Francisco, CA

from $11 / 01 / 93$ thru $11 / 05 / 93$

\section{DISCLAIMER}

This report was prepared as an account of work sponsored by an agency of the United States Government. Neither the United States Government nor any agency thereof, nor any of their employees, makes any warranty, express or implied, or assumes any legal liability or responsibility for the accuracy, completeness, or usefulness of any information, apparatus, product, or process disclosed, or represents that its use would not infringe privately owned rights. Reference herein to any specific commercial product, process, or service by trade name, trademark, manufacturer, or otherwise does not necessarily constitute or imply its endorsement, recommendation, or favoring by the United States Government or any agency thereof. The views and opinions of authors expressed herein do not necessarily state or reflect those of the United States Government or any agency thereof.

\section{MASTER}

\section{DOE Contract No. DE-AC09-89SR18035}

This paper was prepared in connection with work done under the above contract number with the U. S. Department of Energy. By acceptance of this paper, the publisher and/or recipient acknowledges the U. S. Government's right to retain a nonexclusive, royalty-free license in and to any copyright covering this paper, along with the right to reproduce and to authorize others to reproduce all or part of the copyrighted paper. 


\section{DISCLAIMER}

This report was prepared as an account of work sponsored by an agency of the United States Government. Neither the United States Government nor any agency thereof, nor any of their employees, makes any warranty, express or implied, or assumes any legal liability or responsibility for the accuracy, completeness, or usefulness of any information, apparatus, product, or process disclosed, or represents that its use would not infringe privately owned rights. Reference herein to any specific commercial product, process, or service by trade name, trademark, manufacturer, or otherwise does not necessarily constitute or imply its endorsement, recommendation, or favoring by the United States Government or any agency thereof. The views and opinions of authors expressed herein do not necessarily state or reflect those of the United States Government or any agency thereof.

This report has been reproduced directly from the best available copy.

Available to DOE and DOE contractors from the Office of Scientific and Technical Information, P. O. Box 62, Oak Ridge, TN 37831; prices available from (615) $576-8401$

Available to the public from the National Technical Information Service, U. S. Department of Commerce, 5285 Port Royal Rd., Springfield, VA 22161 


\title{
Title of Paper: Problems and Solutions in Application of IEEE Standards at Savannah River Site, Department of Energy (DOE) Nuclear Facilities
}

\author{
Author: Young S. Lee, Co-authors: T. L Bowers, B. J. Chopra, T. T. Thompson \\ E. W. Zimmerman, Westinghouse Savannah River Company
}

\section{Abstract:}

The Department of Energy (DOE) Nuclear Material Production Facilities at the Savannah River Site (SRS) were designed, constructed, and placed into operation in the early 1950's, based on existing industry codes/standards, design criteria, analytical procedures. Since that time, DOE has developed Orders and Polices for the planning, design and construction of DOE Nuclear Reactor Facilities which invoke or reference commercial nuclear reactor codes and standards.

The application of IEEE reactor design requirements such as Equipment Qualification, Seismic Qualification, Single Failure Criteria, and Separation Requirement, to nonreactor facilities has been a problem since the IEEE reactor criteria do not directly confirm to the needs of non-reactor facilities.

Therefore, SRS Systems Engineering is developing a methodology for the application of IEEE Standards to nonreactor facilities at SRS. The first product of the team efforts is an "Application of IEEE 308-1980 to SRS NonReactor Applications".

\subsection{INTRODUCTION}

DOE Order 6430.1A is the controlling DOE document for design of DOE non-reactor facilities. This Order in turn invokes other DOE Orders, government regulations, and industry codes and standards as appropriate for systems and equipment within DOE facilities. In the case of safety class (as defined in DOE Order 6430.1A) equipment and systems, Section 1660-99.0.1 in DOE Order 6430.1A specifically requires that "safety class components and systems are subject to the basic approach outlined in the IEEE 308 ? standards and to higher quality assurance requirements as needed". DOE Order 6430.1A does not provide guidance or identification of the "basic approach" that is to be applied.

As identified by its title and content, IEEE-308-1980 was written specifically for use in commercial nuclear power generating stations for the safety class electrical systems and components; safety class electrical systems and components are designated "Class $1 E$ " in commercial power generating stations and the IEEE standards. As issued, IEEE-308-1980 was not intended for use outside a commercial nuclear power generating station.

DOE Order 6430.1A, Section 1660-99.0.1, attempts to utilize the intent and content of this commercial reactor standard in non-reactor nuclear facilities, but Section 1660 99.0.1 fails to give guidance to the user on specifics in the application of the "basic approach outlined in IEEE-308". A study was undertaken to determine what is the IEEE-308 "basic approach", and how it can be applied at DOE facilities in non-reactor applications consistent with the principles and requirements of DOE Order 6430.1A. Since the overriding requirement is conformance with DOE Order 6430. 1 A, it was determined that any portions of IEEE-3081980 which are specific to reactor design or features and commercial reactors in particular, and are thus inappropriate to non-reactor applications, will not be utilized in nonreactor facilities. Similarly, where the IEEE-308-1980 requirements are more general in nature and can be directly used or modified for non-reactor applications, they will be utilized, but only within the concepts and requirements contained in DOE Order 6430.1 A. Word substitution with words and phrases already defined in DOE Order 6430.1 A are utilized wherever possible.

Some words and phrases defined in IEEE 308 have been quoted in the paper to compare the concepts and the requirements between IEEE 308 and DOE Order 6430.1 A. However, there is no intent to establish new procedures, practices, or policies which violates IEEE copyright, but simply to provide guidance in the consistent application of IEEE-308-1980 to non-reactor nuclear facilities at SRS as required by DOE Order 6430,1 A.

\subsection{USE OF IEEE 308-1980 CRITERIA}

The following is the methodology for application of the "IEEE-308 basic approach" in non-reactor nuclear applications in DOE facilities at SRS. Application of these criteria will result in the use of IEEE 308-1980 as required by DOE Order 6430.1A. 


\subsection{General:}

The use of IEEE-308-1980 in non-reactor nuclear applications shall not result in th designation of "Class IE" for safety class electrical equip nent and systems, and further shall be applied in a manner consistent with the requirements of DOE Order $6430.1 \mathrm{~A} ; 6430.1 \mathrm{~A}$ criteria shall apply in the event of any conflicts or discrepancies. The intent is that the criteria contained in IEEE-308-1980, as modified by the instructions in Section 5.0 of this guide, shall be used as requirements for the design of a facility or a project.

\subsection{Word Substitution:}

The utilization of IEEE-308-1980 in many cases will involve simple word substitutions to conform to DOE Order 6430.1A usage or site usage and practices. Such substitutions are summarized below:

1) "Safety Class" is substituted for "Class 1E" in IEEE308. This provides the consistency between the term "Class $1 E^{\prime}$ in IEEE-308 and "safety class" in DOE Order 6430.1A, as both terms refer to a special group of electrical systems and components which are related to or associated with nuclear safety concerns and protection.

2) "Normal power" is substituted for "preferred power". DOE Order 6430.1A uses "normal power", and describes it as the "preferred" power supply for both normal and emergency applications.

3) "Emergency power" is substituted for "standby power". The use of "standby power" in IEEE-308 refers to an alternative power source to be used in emergency conditions that could arise from the loss of the preferred power supply to a commercial reactor. In DOE Order 6430.1A, standby power has a coupletely different intent and purpose; it is simply another power source alternative to the normal power supply, and need not have capabilities for automatic switchover, reliability, etc., associated with emergency power supplies. In contrast, the 6430.1A use of "emergency power" does have all the design and operational features associated with "standby power" in IEEE-308.

4) "Facility" is substituted for "unit" and/or "station".

5) "Non-reactor facility" is substituted for "power generating station".

6) "Design basis accidents" is substituted for "design basis events" consistent with the usage in DOE Order 6430.1A.

7) "Control room" is substituted for "main control room" and/or "central control room", as the control rooms in nonreactor facilities will include any and all control rooms.

\subsection{Other IEEE Standards}

Other IEEE standards referenced in IEEE-308-1980 shall be used as information in non-reactor nuclear applications until specific guidance for their use is provided in the SRS standards. In all cases, DOE Order 6430. LA criteria shall apply.

\subsection{DEFINITIONS}

The definitions below are consistent with the details and intent contained in DOE Order,6430. 1A. The words in italic provides a brief description for the change(s).

3.1 Substitute the following for the definition of "Class 1E": "Safety Class (Electrical). The safety classification of electrical equipment and systems that provide electrical power to other equipment and/or systems that are designated as Safety Class in accordance with DOE Order 6430.1A, and which require electrical power to perform their designated safety function." This definition for safety class is consistent with the details and intent contained in DOE Order 6430. LA.

3.2 Replace the definition of "design basis events" with the following: "For purposes of this document, design basis events conform with and are identical, in every manner and description, to design basis accidents as defined in DOE Order 6430.1A, Glossary." This relates the IEEE-308 usage of design basis events/accidents to that in DOE Order 6430. LA.

3.3 Replace the definition of "engineered safety features" with the following: "engineered safety features. Features provided to prevent or mitigate postulated design basis accidents; safety class systems. The definition of such features shall be consistent with that provided in the glossary of DOE Order 6430.1A." This relates the IEEE-308 usage of engineered safety features to the usage in DOE Order 6430. LA.

3.4 Replace the IEEE-308 definition for a "nuclear power generating station" with the following definition for a "nonreactor nuclear facility": "Non-Reactor Nuclear Facility. Any facility whose function and purpose is consistent with the definition for a "Nuclear Facility" provided in the glossary of DOE Order 6430.LA." This substitution replaces a term with no non-reactor application with a term consistent with $D O E$ Order 6430. LA.

3.5 Add the following definition for "normal power sup- 
ply":

"Normal power supply. That power supply which is preferred to furnish electric energy under all operating conditions, including pre-accident, accident, and postaccident conditions. For purposes of this document, "normal power" and "preferred power" are synonymous." This provides a definition consistent with the usage in DOE Order 6430. LA, and provides a link to the IEEE-308 use of "preferred power".

3.6 Replace the current definition of "preferred power supply" with the following: "Preferred power supply. Refer to "normal power supply" defined above." The IEEE-308 definition is altered for consistency with DOE Order 6430. $2 \mathrm{~A}$.

3.7 Replace the current definition of "protection system" with the following": "Protection system. That part of the sense and command features involved in generating those signals used primarily for the safety systems and engineered safety features." Replaces reactor-specific wording with generic wording applicable to non-reactor uses.

3.8 Add the following definition for a "safety class system": "Safety class system. The safety classification of electrical equipment and systems that provide electrical power to other equipment and/or systems that are designated as Safety Class in accordance with DOE Order 6430. LA, and which require electrical power to perform their designated safety function." This definition is consistent with the content and intent of the DOE Orders, and specifically DOE Order 6430. LA.

3.9 Substitute the following for the definition of "safety function": "Safety function. One of the processes or conditions essential to maintain plant parameters within acceptable limits established for a design basis event. Note: A safety function is achieved by the completion of all required protective actions by the safety system and the engineered safety features concurrent with the completion of all required protective actions by the auxiliary supporting features." The IEEE-308 definition for safety function includes as examples, "emergency negative reactivity insertion, post accident heat removal, emergency core cooling, post accident radioactivity removal, and containment isolation"; these examples ure omitted from this guide since they are not applicable to non-reactor facilities. Further, "safety system" has been used to substitute for the IEEE-308 "reactor trip system".

3.10 Replace the IEEE-308 definition for "safety system" with the following: "Safety system. Those systems (safety class items and engineered safety features, including all auxiliary supporting features and other auxiliary features) which provide a safety function. A safety system is comprised of more than one safety group of which any one safety group can provide the safety function." Replaces reactor-specific terminology with more general terminolngy which is consistent with DOE Order 6430.24.

3.11 Replace the definition of "standby power supply" wich the following definition for "emergency power supply": "Emergency power supply. The power supply that is provided to safety class equipment and/or systems to allow them to maintain their safety class functions during periods of partial or total power failure of the normal power system." The definition for "emergency power supply" replaces the IEEE-308 definition for "standby power supply". "Standby power supply" as used for nuclear power generating stations has a very specific and narrow usage as the system used to supply electrical power to the station customers when the electrical power output from the reactor is unavailable. In the truest sense, the "standby power" is really an emergency system, and is thus consistent with the intent and usage of "emergency power" from DOE Order 6430. LA.

3.12 Omit the definition of "unit": "Unit", as used in IEEE-308, is inappropriate for and not applicable to nonreactor nuclear applications.

\subsection{REFERENCE}

In Section 4.0 of IEEE 308, References, include the following statement at the beginning of the section: "The following references are not requirements, but may be used for guidance to supplement other specific requirements."

The IEEE-308 references are generally intended to be requirements. This statement clarifies the use of these references consistent with the use of DOE Order 6430.LA. Only those IEEE standards specifically invoked by $6430.2 \mathrm{~A}$ are requirements, and thus only IEEE-379 and IEEE-384 are requirements, but only as invoked by DOE Order 6430. LA.

\subsection{APPLICATION OF IEEE 308-1980 CRITERIA}

The following constitute clarifications, alterations, or deletions of IEEE-308-1980 criteria for use in SRS nonreactor applications. Conformance with these criteria will result in the proper application of IEEE-308 criteria consistent with the concepts and the requirements of DOE Order 6430.1A. This Section covers the affected subsections only. The words in italic provides a brief description for the change(s).

5.1 In section 5.1 of IEEE 308, General, omit subparagraph (2). This condition is not applicable to nonreactor facilities, and is omitted. 
5.2 In Section 5.2 of IEEE 308, Relationship Between Safety System and Safety Class Power System, replace the first paragraph with the following: "Those portions of the Safety Class power system that are required to support Safety Systems in the performance of their safety functions shall meet the requirements of DOE Order 6430.1A, Sections 1300 and $1660-99.0$. In addition, those other normal components, equipment, and systems (that is, overload devices, protective relaying, etc.) within the Safety Class power system that have no direct safety function and are only provided to increase the availability or reliability of the Safety Class power system shall meet those requirements in DOE Order 6430.1A, Section 1660-99.0.4 to assure that those components, equipment, and systems do not degrade the Safety Class power system below an acceptable level. The requirements contained in IEEE Std. 603-1980 may be used as guidance in non-reactor applications."

IEEE-308 requires compliance with IEEE Standard 603-1980. References to the appropriate sections of DOE Order 6430. LA have been substituted for IEEE-603, and a sentence is added that invokes IEEE-603 as a guidance document, not a requirement. A separate evaluation of the use of IEEE-603 will be provided in another SRS guide.

5.3 In Section 5.2 of IEEE 308, Relationship Between Safety System and Safety Class Power System, replace the second, third, and fourth paragraphs with the following: "The safety system criteria that these elements would not have to meet include, but are not necessarily limited to, the criteria described in IEEE Std 603-1980 for operating bypass, maintenance bypass, and bypass indication. The criteria in IEEE Std 603-1980 may be used for guidance. An analysis shall be made to assure that when these components, equipment, or systems are utilized, the consequences of any operation or failure is acceptable to the Safety Class power system.

Components, equipment or systems required to provide some protective action, such as containment integrity protection, or utilized to provide isolation protection are described in IEEE Std 603-1980. IEEE Std 603-1980 may be used as guidance.

Figures 2, 3, 4, 5, and 6 illustrate both the overall and detailed relationship between the Safety Class power system and their components."

The above paragraphs have been reworded to change the use of IEEE standard 603-1980 from a requirement to a standard that is to be consulted as guidance. An interpretation of the application of 603-1980 will be provided in a separate SRS guide later.

5.4 In Section 5.4 of IEEE 308, Power Quality, replace the current requirements with the following: "The variations of voltage and frequency in the Safety Class power systems during any design basis event shall not degrade the performance of any safety system load below an acceptable level such that the intended safety function(s) cannot be performed." IEEE-308 contains references to systems and boundaries which are specific to reactors and reactor systems. The wording change reflects the intent of protection of safety functions.

5.5 In Section 5.5 of IEEE 308, Design Basis, replace the first paragraph with: "A specific design basis shall be provided for the Safety Class power systems. The design basis shall include as a minimum. This change eliminates reactor-specific terms.

In subparagraphs (1) to (10), substitute "emergency generators" for "standby generators". "Emergency" is substituted for "standby" in IEEE-308. As described previously, DOE Order 6430.LA use of "emengency" is consistent with the intent and usage of "standby" in IEEE-308.

5.6 In Section 5.7 of IEEE 308, Identification, substitute the following: "Components of Safety Class power systems and their associated design, operating, and maintenance documents shall be marked or labeled in a distinctive manner. ANSI/IEEE Std 494-1974 may be used as guidance in the identification of maintenance documents."

The paragraph is altered to utilize IEEE-494 1974 as guidance rather than a requirement.

5.7 In Section 5.8 of IEEE 308, Independence, replace the contents with: "Independence of equipment and circuits shall be in accordance with the criteria in DOE Order 6430.1A, Section 1660-99.0.1." The requirement for independence is altered to utilize the specifications in the DOE Order rather than in IEEE-384.

5.8 In Section 5.9 of IEEE 308, Equipment Qualification, substitute the following: "Safety Class power system equipment shall be qualified in accordance with the requirements of DOE Order 6430.1A, Section 1300-3.4."

The referenced DOE Order 6430. LA section contains criteria relevant to the application of equipment qualification.

5.9 In Section 5.10 of IEEE 308, Single Failure Criterion, replace the first sentence with: "The Safety Class power system shall support the performance of all safety functions in accordance with DOE Order 6430.1A, Sections 1300-3.3 and 1660-99. The following shall be considered.

1) any single detectable failure within the Safety Class power system or the safety systems concurrent with all identifiable, but nondetectable, failures;

(2) all failures caused by the single failure;

(3) all failures and spurious system actions which cause, or are caused by, the design basis event requiring the safety functions. The single failure criterion applies whether control 
is by automatic or manual means. IEEE Std 379-1977 provides guidance on the application of the single failure criterion to the design." The referenced sections of DOE Order 6430.LA contain requirements for the application of single failure criteria.

5.10 Replace the third paragraph in Section 5.10 of IEEE 30)8 with: "ANSI/IEEE Std 352-1975 and ANSI/IEEE Std $577-1976$ may be used as guidance for probabilistic risk assessment. This will alter the use of these IEEE standards as guidance only consistent with DOE Order 6430. LA.

5.11 Replace the fourth paragraph in Section 5.10 of IEEE 308 with: "Where reasonable indication exists that a design which meets the single failure criterion may not satisfy all the reliability requirements specified in 4.9 of IEEE Std 6()3-1980, a probabilistic assessment of the safety system should be performed. The assessment shall not be limited to single failures. If the assessment shows that the design basis requirements are not met, design features shall be provided, or corrective modifications shall be made to ensure that the system meets the specified reliability requirements." The reference in IEEE-308 to section 3.9 appears to be in error, and 4.9 appears to be the correct reference.

5.12 In Section 5.11 of IEEE 308, Connection of NonSafety Class Circuits, replace the entire section with: "NonSafety Class circuits may be supplied from Safety Class power systems, provided that Safety Class systems are not degraded below an acceptable level. These non-Safety Class circuits shall meet the independence requirements as established in DOE Order 6430.1A, Section 1660-99.0." DOE Order 6130.LA is referenced for the criteria for independence requirements rather than IEEE-384-1977.

5.13 Omit Section 5.13. Section 5.13 of IEEE.308 is inappropriate for non-reactor applications at SRS.

5.14 In Section 6.1.1 of IEEE 308, Description, replace the section with: "The Safety Class power systems may consist of an alternating current power system, a direct current power system, and a vital instrumentation and control power system. Figure 1 illustrates one possible arrangement of the Safety Class power systems."

"Shall" in IEEE-308 has been changed to "may" to better represent conditions in non-reactor facilities.

5.15 In Section 6.2.2 of IEEE. 308, Distribution system, in the third subparagraph, Independence: Substitute "DOE Order 6430.1A, Section 1660-99.0.1" for "IEEE Std 384 1977", "Safety Class" for "Class IE". DOE Order 6430. LA has been substituted for IEEE-384-1977 to provide independence criteria.
5.16 Omit Section 6.2.3 of IEEE 308, Preferred Power Supply in its entirety. "Preferred Power Supply" criteria, as utilized for reactors, is not appropriate for non-reactor applications.

5.17 In Section 6.2.4 of IEEE 308, Standby Power Supply, replace subparagraph 6, Capacity, with: "Each emergency power source shall be capable of energizing or starting and accelerating to rated speed, in the required sequence, all the required safety system loads. For requirements on diesel generators refer to ANSI/IEEE Std $387-1977$ as a guide." As described above in the definitions section, "emergency power" has been substituted for "standby power".

5.18 Replace subparagraph 7, Energy Storage (including subsets (a) and (b)) with: "Stored energy (fuel) at the site shall have the capacity to operate the emergency power supply while supplying post accident power requirements of the facility for a period described in the Functional Performance Requirements (FPR) and/or Safety Analysis Report (SAR) documents for the project or facility."

IEEE-308 provides specific periods for enengy storage (e.g., 7 days or the time required to replenish the source). Such requirements are not applicable to non-reactor applications at $S R S$, and the criteria provided in the FPR and/or SAR are instead referenced.

5.19 In Section 6.2.6 of IEEE 308, Test Provisions, replace the first paragraph with the following: "Means shall be provided to start and test load the emergency generators while the facility is operating (ANSI/IEEE Std 387-1977 may be used as a guide) in addition to the following:" The use of IEEE-387 is change from a requirement to a guide, consistent with the requirements of DOE Order 6430.1A. Note that subsets (1) and (2) are not changed

5.20 In Section 6.3.2 of IEEE 308, Distribution System, replace the first sentence in subset (3), Independence, with: "Distribution circuits to redundant equipment shall be physically and electrically independent of each other in accordance with DOE Order 6430. LA, Section 1600-99.0." DOE Order 6430. LA is substituted for IEEE-384 as the basis for the requirement.

5.21 In Section 6.3.4 of IEEE 308, substitute "6.3.1(4)" for "5.3.1(4)". This corrects a typographical error in IEEE-308.

5.22 In Section 6.5.1 of IEEE 308, General, in the second sentence, substitute "The execute features shall consider" for "The execute features are subject to the". "Shall consider" replaces "are subject to" for the use of IEEE-603. IEEE-603 guidance will be provided in a separate guide later.

5.23 In Section 6.5.2 of IEEE 308, Manual Control, 
replace the section with: "If manual control of any actuated equipment in the execute features is required to fulfill a design basis or testing objective, the features necessary to accomplish such manual control shall:

(1) Be Safety Class

(2) Meet the requirements of 6.5 .1

(3) Be shown by analysis not to defeat manual initiation. The requirements of IEEE Std 603-1980, Section 6.2, shall be considered." The intent is changed to require only consideration of the IEEE-603 requirements.

5.24 In Section 7.5.1 of IEEE 308, Periodic System Tests, substitute the following: "7.5.1 The system tests referred to in 7.3 shall be performed at scheduled intervals. IEEE Std 338-1977 may be used for guidance." IEEE-338 is included as guidance until it can be evaluated for direct and complete application to non-reactor facilities. IEEE-308 requires adherence to IEEE-338.

5.25 Section 8 of IEEE 308, Multi-Unit Station Considerations: Omit entire Section 8.0. The requirements for a "multi-unit station" provided in IEEE-308 are not applicable outside a reactor.

5.26 Figure 1. Omit switchyard equipment specific for commercial reactor as per the attached revised figure.

The generator and auxiliary power supply/transformer are reactor-specific and not typical for non-reactor applications.

5.27 Figure 2. Add footnote to identify that the figure is for illustrative purposes. Items identified as post-accident heat removal, recirculation spray system, and containment spray system, are specific to reactors, but are also illustrative of non-reactor applications.

5.28 Figure 4. Modify the heading at the left of the top row to substitute "Safety Function Actuation Features" for "Reactor Trip System and Engineered Safety Features".

This change, in conjunction with previous changes, renders the figure applicable to non-reactor uses.

5.29 Figure 5. Modify the heading at the left of the top row to substitute "Safety Function Actuation Features" for "Reactor Trip System Engineered Safety Features". Also, in the center block in the topmost row, omit the item "RTS Trip Breakers". Renders the figure applicable non-reactor uses.

5.30 Figure 6. Modify the heading at the left of the top row to substitute "Safety Function Actuation Features" for "Reactor Trip System and Engineered Safety Features". This change, in conjunction with previous changes, renders the figure applicable to non-reactor uses.

\subsection{REFERENCES}

6.1 DOE Order 6430.1A, "General Design Criteria", 4-61989.

6.2 IEEE 308-1980, "IEEE Standard Criteria for Class IE Power Systems for Nuclear Power Generating Stations", The Institute of Electrical and Electronics Engineers, Inc., 1980. 

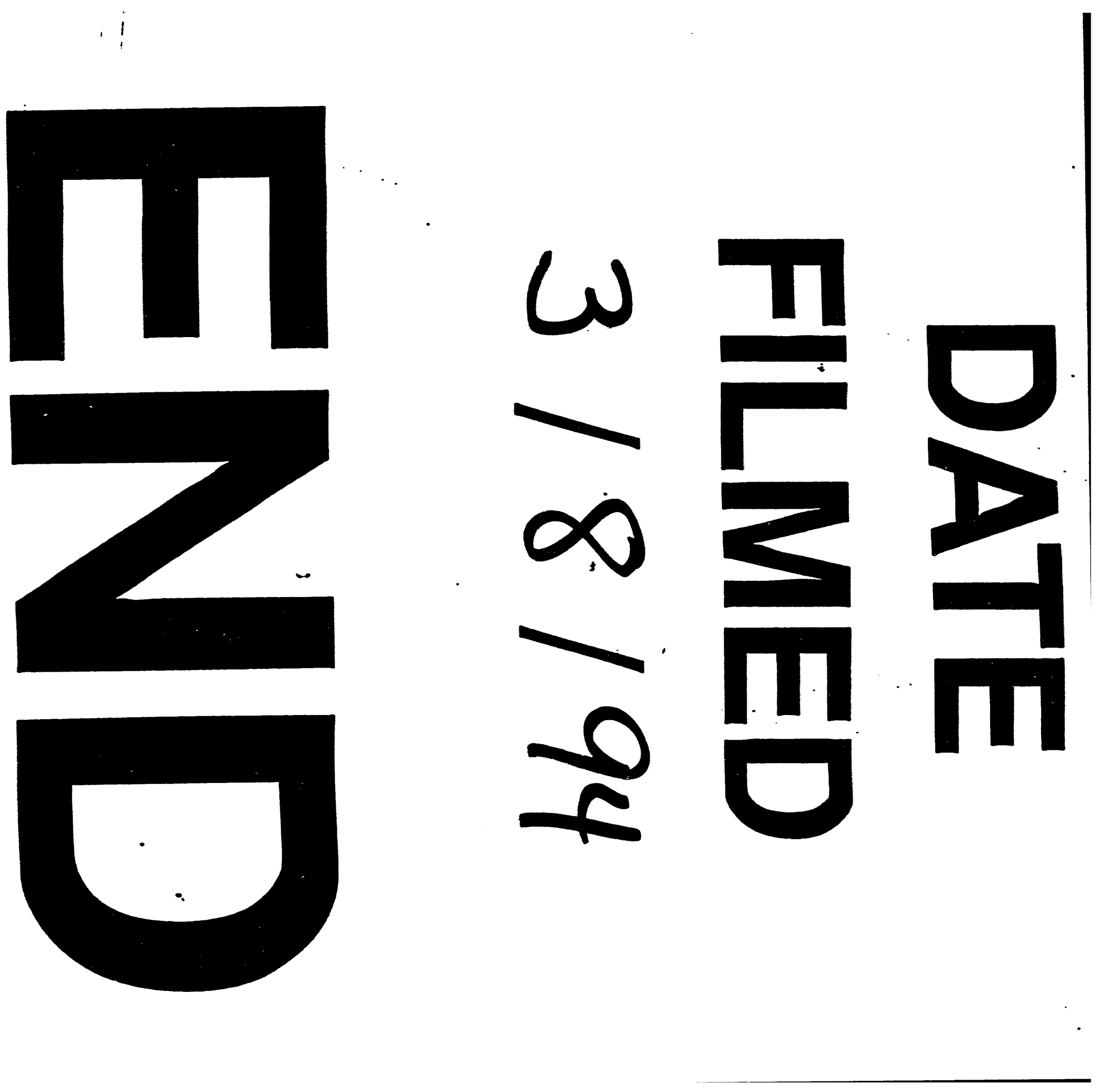


$$
\text { - ndm }
$$

